
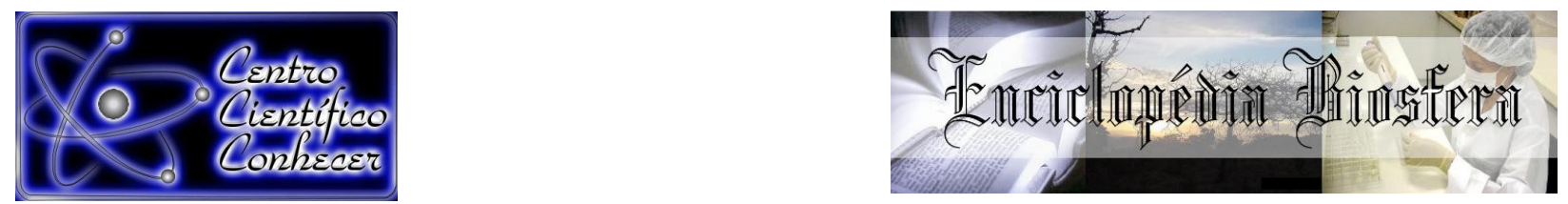

\title{
DOSES E FONTES DE FÓSFORO SOB A EFICIÊNCIA NUTRICIONAL DE GENÓTIPOS DE FEIJÃO-CAUPI
}

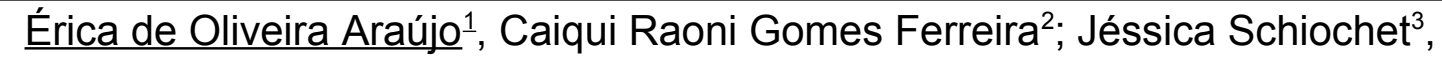
Wilk Sampaio de Almeida ${ }^{4}$

${ }^{1}$ Prof.(a) Doutora do Departamento de Agropecuária do Instituto Federal de Educação, Ciência e Tecnologia do Amazonas, Campus de Humaitá, HumaitáBrasil.email:ericabb25@hotmail.com

2Discente do Curso de Engenharia Agronômica do Instituto Federal de Educação, Ciência e Tecnologia de Rondônia, Campus de Colorado do Oeste, Colorado do Oeste - Brasil

${ }^{3}$ Discente do Curso de Engenharia Agronômica do Instituto Federal de Educação, Ciência e Tecnologia de Rondônia, Campus de Colorado do Oeste, Colorado do Oeste - Brasil

${ }^{4}$ Prof. Mestre do Departamento de Agronomia do Instituto Federal de Educação, Ciência e Tecnologia de Rondônia, Campus de Colorado do Oeste, Colorado do Oeste - Brasil.

Recebido em: 06/04/2018 - Aprovado em: 10/06/2018 - Publicado em: 20/06/2018 DOI: 10.18677/EnciBio_2018A37
}

\begin{abstract}
Em virtude do alto custo dos fertilizantes fosfatados, e também, da sua adsorção, torna-se necessária à busca por genótipos, fontes e doses de $\mathrm{P}$ que possam maximizar a eficiência de utilização do nutriente pela cultura do feijão-caupi, refletindo em máximas produtividades com baixo custo. Neste sentido, objetivou-se com o presente trabalho avaliar os efeitos das doses e fontes de $\mathrm{P}$ solúvel sobre os parâmetros fitotécnicos e absorção de fosforo por diferentes genótipos de feijãocaupi cultivado em ambiente protegido. O delineamento experimental utilizado foi o de blocos casualizados em esquema fatorial $4 \times 2 \times 2$, sendo, quatro doses de fósforo $\left(0,40,80\right.$ e $\left.120 \mathrm{~kg} \mathrm{ha}^{-1}\right)$, duas fontes solúveis de $\mathrm{P}_{2} \mathrm{O}_{5}$ (SFS $\left(21 \% \mathrm{P}_{2} \mathrm{O}_{5}\right)$ e SFT $(44 \%$ $\left.\mathrm{P}_{2} \mathrm{O}_{5}\right)$ ) e dois cultivares de feijão-caupi (Tumucumaque e Novaera), com quatro repetições. Os resultados permitiram concluir que há variabilidade quanto à eficiência e reposta à aplicação de fósforo entre os genótipos de feijão-caupi. $O$ genótipo Novaera mostrou-se mais eficiente quanto à absorção e transporte de fósforo. O superfosfato triplo apresenta maior eficiência na absorção de $P$ pelas raízes que o superfosfato simples. O aumento nas doses de fósforo promove incremento nas concentrações e na eficiência de utilização do fósforo por plantas de feijão-caupi.
\end{abstract}

RESUMO

PALAVRAS-CHAVE: Ambiente protegido, Estado nutricional, Novaera, Tumucumaque, Vigna unguiculata (L.). 


\title{
RATES AND SOURCES OF PHOSPHORUS IN THE NUTRITIONAL EFFICIENCY OF GENOTYPES OF COWPEA
}

\begin{abstract}
Due to the high cost of phosphate fertilizers, and also their adsorption, it is necessary to search for genotypes, sources and doses of $P$ that can maximize the efficiency of nutrient utilization by cowpea, reflecting maximum yields with low cost. In this sense, the objective of this work was to evaluate the effects of doses and sources of soluble $P$ on the phytotechnical parameters and absorption of phosphorus by different genotypes of cowpea cultivated in protected environment. The experimental design was completely randomized in a $4 \times 2 \times 2$ factorial scheme, with four phosphorus doses $\left(0,40,80\right.$ and $\left.120 \mathrm{~kg} \mathrm{ha}^{-1}\right)$, two soluble sources of $\mathrm{P}_{2} \mathrm{O}_{5}\left(\mathrm{SFS}\left(21 \% \mathrm{P}_{2} \mathrm{O}_{5}\right)\right.$ and SFT $\left(44 \% \mathrm{P}_{2} \mathrm{O}_{5}\right)$ and two cultivars of cowpea (BRS Tumucumaque and BRS Novaera), with four replicates. The results conclude that there is variability as to the efficiency and application of phosphorus response among genotypes of cowpea. The genotype Novaera proved to be more efficient as the absorption and transport of phosphorus. The triple superphosphate offers greater efficiency in the absorption of $\mathrm{P}$ by the roots the superphosphate. The increase in rates of phosphorus promotes increase in the concentrations and phosphorus utilization efficiency by cowpea plants.
\end{abstract}

KEYWORDS: Protected environment, Nutritional status, Novaera, Tumucumaque, Vigna unguiculata (L.).

\section{INTRODUÇÃO}

A área mundial plantada de feijão-caupi (Vigna unguiculata (L.) Walp) é 10,4 milhões de hectares, e está localizada principalmente nas regiões tropicais e subtropicais da América, Ásia e África; a produção mundial de grãos de feijão-caupi é de cerca de 5,5 milhões toneladas, e a Nigéria é o maior produtor mundial (FAO, 2016). No Brasil estima-se que é cultivado em torno de 1,5 milhões de hectares de feijão-caupi, com produtividade média de aproximadamente $400 \mathrm{~kg} \mathrm{ha}^{-1}$ (EMBRAPA, 2017), o que permite a cultura figurar entre as principais leguminosas cultivadas no País, predominantemente nas regiões Norte e Nordeste (SILVA et al., 2010a). Porém, baixos níveis de produtividade têm sido observados nas áreas produtoras $\mathrm{e}$ uma das principais causas é a baixa disponibilidade de nutrientes no solo, particularmente pelo insuficiente suprimento de fósforo (P) (ARAUJO et al., 2012).

Em solos tropicais, a prática da adubação fosfatada é imprescindível para a obtenção de produtividades adequadas pela maioria das culturas de interesse econômico (KARIKARI et al., 2015). O P é fundamental para o rendimento de feijãocaupi por estimular o crescimento, iniciar a formação de nódulos, bem como influenciar a eficiência da simbiose rhizobium vegetal (NKAA et al., 2014). Pesquisas realizadas por Karikari et al., (2015), revelaram alto potencial de resposta à adubação fosfatada pela cultura do feijão-caupi em solos caracterizados pela baixa disponibilidade de $\mathrm{P}$, contribuindo significativamente para o aumento do crescimento vegetativo, nodulação e rendimento de grãos.

Além da aplicação de adubos fosfatados, a forma como esses insumos são aplicados deve ser também considerada no manejo das culturas, uma vez que os solos tropicais geralmente apresentam elevado poder de adsorção de fosfatos; e em função dessas elevadas taxas de adsorção, a aplicação localizada deste nutriente pode ser mais vantajosa, em solos com baixos teores de $\mathrm{P}$ disponível. No entanto, a aplicação localizada de $\mathrm{P}$ deve ser adotada com cautela, pois embora tenha a vantagem de reduzir temporariamente a adsorção deste elemento pelo solo, 
contribui para a redução do volume de raízes. Há, de modo geral, maior crescimento de raízes, de modo particular de raízes mais finas, no local da aplicação da fonte de $\mathrm{P}$, o que pode compensar, parcial ou totalmente, a baixa disponibilidade de $\mathrm{P}$ fora desse local (BARBER, 1995).

Dentre as fontes de $\mathrm{P}$ solúvel existentes, o superfosfato simples (SFS) e o superfosfato triplo (SFT) são as mais utilizadas e, em solos altamente intemperizados, são aplicadas doses altas, devido ao processo de adsorção aos argilominerais e óxidos de ferro e alumínio (SILVA et al., 2010b). O SFS tem a vantagem de também adicionar $S$ para o solo e, consequentemente, suprir as necessidades das plantas com este elemento. Por outro lado, o SFT apresenta maior concentração de $\mathrm{P}_{2} \mathrm{O}_{5}$, diminuindo a quantidade bruta a ser aplicada na adubação (SILVA et al., 2010b).

O uso de genótipos e/ou variedades eficientes na absorção e na utilização de fósforo pode ser outra solução complementar importante para aumentar a produtividade e reduzir o custo de produção. Diversos trabalhos têm sugerido que além de melhores técnicas de adubação e correção dos solos, a seleção de cultivares mais tolerantes ao alumínio e mais eficientes na absorção e utilização de fósforo e demais nutrientes são importantes (WANG et al., 2010).

Neste sentido, para obter alta produtividade de grãos de feijão-caupi é necessária, além da utilização da adubação fosfatada a seleção de genótipos eficientes que possibilitem maiores retornos econômicos. Conhecer o efeito da adubação fosfatada no solo e na planta e a sua resposta em diferentes genótipos auxilia no manejo deste nutriente. No entanto, existem poucas informações sobre adubação fosfatada para a cultura do feijão-caupi no estado de Rondônia, o que indica a necessidade da realização de estudos para subsidiar a recomendação das doses e fontes de fósforo. Diante do exposto, o presente trabalho teve por objetivo avaliar os efeitos das doses e fontes de $P$ solúvel sobre os parâmetros fitotécnicos $\mathrm{e}$ absorção de fosforo por diferentes genótipos de feijão-caupi cultivado em ambiente protegido.

\section{MATERIAL E MÉTODOS}

O experimento foi realizado em ambiente protegido do Setor de Produção Vegetal do Instituto Federal de Educação, Ciência e Tecnologia de Rondônia, Campus de Colorado do Oeste, RO, cujas coordenadas geográficas são $13^{\circ} 06^{\prime} \mathrm{S}$ e $60^{\circ} 29^{\prime} \mathrm{W}$, com altitude média de 407 metros. O clima regional, segundo a classificação de Koppen, é do tipo Am, tropical quente e úmido com duas estações bem definidas e médias anuais, respectivamente, de temperatura e precipitação pluviométrica variando de $24^{\circ} \mathrm{C}$ a $26^{\circ} \mathrm{C}$ e de $1900 \mathrm{~mm}$ a $2200 \mathrm{~mm}$ (ALVARES et al., 2013). A amostra de solo utilizada foi coletada na profundidade de $0-20 \mathrm{~cm}$.

A análise química da amostra de solo antes da instalação do experimento resultou nos seguintes valores: M.O.: 28,90 g dm${ }^{-3} ; \mathrm{pH}\left(\mathrm{CaCl}_{2}\right): 6,1 ; \mathrm{P}: 10 \mathrm{mg} \mathrm{dm}^{-3}$;

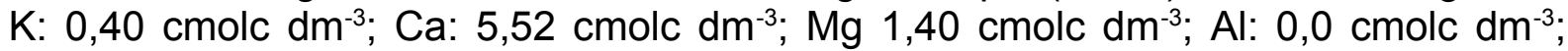
$\mathrm{H}+\mathrm{Al}: 2,10 \mathrm{cmolc} \mathrm{dm}^{-3}$; SB: 7,32 cmolc $\mathrm{dm}^{-3}$; CTC: 9,42 $\mathrm{cmolc} \mathrm{dm}^{-3}$, saturação por bases $77 \%$. A análise granulométrica apresentou $428 \mathrm{~g} \mathrm{~kg}^{-1}$ de areia, $210 \mathrm{~g} \mathrm{~kg}^{-1} \mathrm{de}$ silte e $362 \mathrm{~g} \mathrm{~kg}^{-1}$ de argila.

O delineamento experimental utilizado foi o de blocos casualizados em esquema fatorial $4 \times 2 \times 2$, sendo, quatro doses de fósforo $\left(0,40,80\right.$ e $120 \mathrm{~kg} \mathrm{ha}^{-1} \mathrm{de}$ $\mathrm{P}_{2} \mathrm{O}_{5}$ ), duas fontes solúveis de $\mathrm{P}_{2} \mathrm{O}_{5}$ (SFS $\left(21 \% \quad \mathrm{P}_{2} \mathrm{O}_{5}\right)$ e SFT $\left(44 \% \mathrm{P}_{2} \mathrm{O}_{5}\right)$ e dois cultivares de feijão-caupi (BRS Tumucumaque e BRS Novaera), com quatro repetições, totalizando 64 unidades experimentais. 
Com base nos resultados da análise química do solo, foi realizada uma adubação de base para garantir o estabelecimento da cultura. Foram aplicados 60 $\mathrm{kg} \mathrm{ha}^{-1}$ de $\mathrm{K}_{2} \mathrm{O}$, na forma cloreto de potássio. As doses de $\mathrm{P}$ e $\mathrm{K}$ foram convertidas para $\mathrm{mg} \mathrm{kg}^{-1}$ utilizando valores de densidade do solo. Os micronutrientes foram aplicados conforme a exigência da cultura.

As unidades experimentais foram compostas por vasos plásticos com capacidade de $12 \mathrm{dm}^{-3}$, preenchidos com solo seco ao ar, passado em peneira de 4 $\mathrm{mm}$ de abertura. A umidade dos vasos foi controlada diariamente, visando manter o solo com $60 \%$ da capacidade de campo. As sementes de feijão-caupi, cultivares BRS Tumucumaque e BRS Novaera foram postas a germinar diretamente nos vasos, sendo, que aos oito dias após a emergência (DAE), realizou-se o desbaste, deixando-se apenas uma planta em cada unidade experimental.

Por ocasião da colheita foram determinadas: a altura de plantas e o diâmetro do caule. A altura das plantas foi obtida pela medição do colo da planta até o meristema apical, utilizando-se uma fita métrica; e o diâmetro do caule foi determinado com o auxílio de paquímetro digital, na altura de $2 \mathrm{~cm}$ do colo da planta. Posteriormente as plantas foram coletadas e divididas em raiz e parte aérea. Em seguida, todo o material vegetal coletado foi lavado em água corrente e água deionizada, respectivamente.

O comprimento de raiz principal foi determinado com uma fita métrica e o volume de raiz pelo método da proveta, no qual as raízes foram submersas em proveta graduada com volume de água destilada conhecido, sendo o volume determinado pela diferença entre o volume inicial e final do recipiente. As amostras foram acondicionadas em sacos de papel e secas em estufa com circulação forçada de ar à temperatura de $65^{\circ} \mathrm{C}$, por 72 horas. Após a secagem do material vegetal, procedeu-se à pesagem e moagem da massa seca em moinho tipo Wiley, sendo as amostras, submetidas à digestão nitro-perclórica, para determinação do teor de $\mathrm{P}$ nas diferentes partes da planta (raiz e parte aérea), de acordo com a metodologia descrita em Embrapa (2009).

$O$ índice de eficiência de absorção do $P$, razão entre o conteúdo total de nutriente na planta e a massa seca das raízes, foi calculado de acordo com Swiader et al. (1994), enquanto que a eficiência de transporte do fósforo, razão entre o conteúdo de $P$ na parte aérea e o conteúdo de $P$ na planta e a eficiência de utilização do fósforo, razão entre a massa seca total produzida e o acúmulo total de nutrientes na planta foram calculados de acordo com Siddiqi e Glass (1981).

Os dados foram submetidos ao teste de normalidade (Shapiro Wilk) e análise de variância com auxílio computacional do programa de análise estatística Sisvar. Os efeitos entre genótipos e fontes de $\mathrm{P}$ foram avaliados pelo teste de Tukey a nível de $5 \%$ de probabilidade. Para a variável com significância estatística em função das doses de $\mathrm{P}$ foi utilizada análise de regressão.

\section{RESULTADOS E DISCUSSÃO}

Houve diferença significativa $(p \leq 0,05)$ entre os genótipos de feijão-caupi para altura de planta, volume de raiz, teor de fósforo na raiz, conteúdo de fósforo na parte aérea e na raiz, eficiência de absorção e transporte de fósforo (Tabela 1 e 2), enquanto que apenas o teor de fósforo na raiz respondeu as diferentes fontes de fósforo solúvel aplicada (Tabela 2). Não houve significância $(p \leq 0,05)$ da interação dos tratamentos para nenhuma das variáveis analisadas. Os resultados evidenciaram efeitos significativos $(p \leq 0,05)$ das doses de fósforo sobre a produção de massa seca, teor de fósforo na parte aérea, conteúdo de fósforo na parte área, 
raiz e na planta, e sob a eficiência de utilização do fósforo por plantas de feijão-caupi (Tabela 1 e 2).

O genótipo Tumucumaque foi estatisticamente superior $(p \leq 0,05)$ ao genótipo Novaera para altura de plantas, volume de raiz, teor e conteúdo de fósforo na raiz (Quadro 3). Resultados inversos foram encontrados para as demais variáveis, na qual a eficiência de absorção e transporte de fósforo por planta de feijão-caupi genótipo Novaera foi superior ao genótipo Tumucumaque (Tabela 3). Esse fato geralmente é devido à existência de comportamento nutricional diferenciado por fatores genéticos de adaptabilidade (ARAÚJO et al., 2012). A absorção de $P$ pelos genótipos de feijão-caupi ficou entre 25,40 e $29,75 \mathrm{mg}$ de peso seco por $\mathrm{g}$ de $\mathrm{P}$ absorvido, e em média $90 \%$ desse $\mathrm{P}$ absorvido foi transportado para diferentes partes da planta.

Corroborando com os resultados encontrados, Araújo et al., (2012), trabalhando com quatro genótipos de feijão-caupi, verificaram diferenças entre os genótipos quanto ao crescimento, teor de $\mathrm{P}$ na parte aérea e na raiz e eficiência de transporte de fósforo. Karikari et al., (2015) verificaram aumento significativo do crescimento vegetativo de plantas de feijão-caupi em resposta à adubação fosfatada, em solos caracterizados pela baixa disponibilidade de $\mathrm{P}$. O aumento ou diminuição do crescimento de raízes pode ajudar a planta a se adaptar a ambientes adversos, tais como baixa disponibilidade de $P$ no solo, entretanto essa diferenciação afeta diretamente a capacidade de absorção de água e nutrientes.

TABELA 1. Valores F, Média e CV para altura de planta (ALT), diâmetro do caule (DIA), volume de raiz (VR), massa seca da parte aérea (MSPA), massa seca da raiz (MSR) e massa seca total (MSTO) de diferentes genótipos de feijão-caupi em resposta a doses e fonte de $\mathrm{P}$ solúvel. Colorado do Oeste, RO (2017).

\begin{tabular}{cccccccc}
\hline Fonte de variação & GL & \multicolumn{7}{c}{ Pr > F } \\
\cline { 3 - 7 } & & DIA & ALT & VR & MSPA & MSR & MSTO \\
\hline Genótipo & 1 & 0,62 & $0,00^{*}$ & $0,04^{*}$ & 0,30 & 0,10 & 0,63 \\
Fonte & 1 & 0,05 & 0,66 & 0,96 & 0,14 & 0,85 & 0,19 \\
Dose & 3 & 0,18 & 0,20 & 0,63 & $0,00^{*}$ & $0,04^{*}$ & $0,00^{*}$ \\
G x F & 1 & 0,75 & 0,26 & 0,90 & 0,36 & 0,76 & 0,47 \\
G x D & 3 & 0,43 & 0,40 & 0,35 & 0,19 & 0,49 & 0,27 \\
F x D & 3 & 0,41 & 0,90 & 0,84 & 0,35 & 0,35 & 0,32 \\
G x F x D & 3 & 0,73 & 0,89 & 0,01 & 0,81 & 0,72 & 0,77 \\
Resíduo & 48 & & & & & & \\
\hline Média & & 10,19 & 0,67 & 25,68 & 22,09 & 2,55 & 24,69 \\
CV (\%) & & 11,03 & 18,37 & 14,66 & 10,81 & 17,39 & 11,08 \\
\hline
\end{tabular}

* - significativo pelo teste de Tukey a $5 \%$ de probabilidade. CV - coeficiente de variação. 
TABELA 2. Valores $F$, Média e $C V$ para teor de $P$ na parte aera (TPPA), teor de $P$ na raiz (TPR), teor de $P$ na planta (TPPL), conteúdo de $P$ na parte aérea (CPPA), conteúdo de $\mathrm{P}$ na raiz (CPR), conteúdo de $\mathrm{P}$ na planta (CPPL), eficiência de absorção de $P(E A P)$, eficiência de transporte de $P(E T P)$ e eficiência de utilização do P (EUP) por diferentes genótipos de feijão-caupi em resposta a doses e fonte de P solúvel. Colorado do Oeste, RO (2017).

\begin{tabular}{|c|c|c|c|c|c|c|c|c|c|c|}
\hline \multirow{2}{*}{$\begin{array}{l}\text { Fonte de } \\
\text { variação }\end{array}$} & \multirow[t]{2}{*}{ GL } & \multicolumn{9}{|c|}{$\operatorname{Pr}>\mathrm{F}$} \\
\hline & & TPPA & TPR & TPPL & CPA & CPR & CPPL & EAP & ETP & EUP \\
\hline Genótipo & 1 & 0,08 & $0,03^{*}$ & 0,83 & $0,04^{*}$ & $0,00^{*}$ & 0,13 & $0,02^{*}$ & $0,00^{*}$ & 0,42 \\
\hline Fonte & 1 & 0,73 & $0,01^{*}$ & 0,22 & 0,15 & 0,29 & 0,22 & 0,34 & 0,18 & 0,44 \\
\hline Dose & 3 & $0,04^{*}$ & 0,51 & 0,38 & $0,01^{*}$ & $0,01^{*}$ & $0,00^{*}$ & 0,24 & 0,07 & $0,00^{*}$ \\
\hline$G \times F$ & 1 & 0,12 & 0,55 & 0,21 & 0,66 & 0,46 & 0,59 & 0,78 & 0,72 & 0,23 \\
\hline$G \times D$ & 3 & 0,43 & 0,61 & 0,59 & 0,08 & 0,12 & 0,09 & 0,60 & 0,13 & 0,76 \\
\hline$F \times D$ & 3 & 0,40 & 0,34 & 0,53 & 0,55 & 0,09 & 0,35 & 0,80 & 0,59 & 0,63 \\
\hline $\begin{array}{l}G \times F \times D \\
\text { Resíduo }\end{array}$ & $\begin{array}{c}3 \\
48\end{array}$ & 0,15 & 0,85 & 0,42 & 0,76 & 0,39 & 0,70 & 0,52 & 0,58 & 0,48 \\
\hline Média & & 2,79 & 2,15 & 4,94 & 61,42 & 24,25 & 66,97 & 27,57 & 91,61 & 9,21 \\
\hline CV (\%) & & 10,40 & 13,55 & 10,16 & 13,94 & 5,55 & 13,06 & 17,61 & 12,37 & 18,55 \\
\hline
\end{tabular}

TABELA 3. Altura de planta (ALT), volume de raiz (VR), teor de $P$ na raiz (TPR), conteúdo de $P$ na parte aérea (CPPA), conteúdo de $P$ na raiz (CPR), eficiência de absorção de $P(E A P)$ e eficiência de transporte de $P$ (ETP) por diferentes genótipos de feijãocaupi cultivados em ambiente protegido. Colorado do Oeste, RO (2017).

\begin{tabular}{cccccccc}
\hline Genótipo & $\begin{array}{c}\text { ALT } \\
(\mathrm{cm})\end{array}$ & $\begin{array}{c}\text { VR } \\
\left(\mathrm{cm}^{3} / \mathrm{planta}\right)\end{array}$ & $\begin{array}{c}\text { TPR } \\
\left(\mathrm{g} \mathrm{kg}^{-1}\right)\end{array}$ & $\begin{array}{c}\text { CPPA } \\
\mathrm{mg}\end{array}$ & $\begin{array}{c}\text { CPR } \\
\mathrm{mg}\end{array}$ & $\begin{array}{c}\text { EAP } \\
\left(\mathrm{mg} \mathrm{g}^{-1}\right)\end{array}$ & $\begin{array}{c}\text { ETP } \\
(\%)\end{array}$ \\
\hline Novaera & $38 \mathrm{~b}$ & $24,06 \mathrm{~b}$ & $2,08 \mathrm{~b}$ & $63,60 \mathrm{a}$ & $5,04 \mathrm{~b}$ & $29,73 \mathrm{a}$ & $92,63 \mathrm{a}$ \\
Tumucumaque & $95 \mathrm{a}$ & $27,31 \mathrm{a}$ & $2,26 \mathrm{a}$ & $59,24 \mathrm{~b}$ & $6,06 \mathrm{a}$ & $25,40 \mathrm{~b}$ & $90,58 \mathrm{~b}$ \\
\hline
\end{tabular}

Médias seguidas da mesma letra na coluna, não diferem estatisticamente entre si pelo teste de Tukey a $5 \%$ de probabilidade.

As doses de $P$ exerceram efeito linear crescente e significativo $(p \leq 0,05)$ sobre a produção de massa seca da parte aérea, da raiz e total (Figura 1A, 1B e 1C), no qual o aumento foi na ordem de $25,86 \%, 31,25 \%$ e $25,30 \%$, respectivamente, com o incremento das doses de $\mathrm{P}$ solúvel aplicada. Esse aumento na produção de massa seca com as doses de $\mathrm{P}$ pode estar associado à disponibilidade de Ca para a planta, já que o P aumenta a disponibilidade do cálcio, componente importante da parede celular das plantas e o solo utilizado no estudo apresentava altos níveis de $\mathrm{Ca}$.

A maior disponibilidade de $\mathrm{P}$ pode desencadear mudanças na fotossíntese, pela maior captação da radiação solar e incremento na produção de fotoassimilados, pois o $\mathrm{P}$ atua como agente formador da molécula de ATP e em condição de baixa produção de ATP o crescimento das plantas é diretamente afetado (ROCHA, 2016). No presente estudo o teor de fósforo no solo considerando o percentual de argila encontrava-se com $10 \mathrm{mg} \mathrm{dm}^{-3}$, teor considerado baixo, o que justifica a resposta linear crescente das variáveis: produção de massa seca da parte aérea, raiz e total em função de doses crescentes de $\mathrm{P}_{2} \mathrm{O}_{5}$ aplicados na semeadura. 

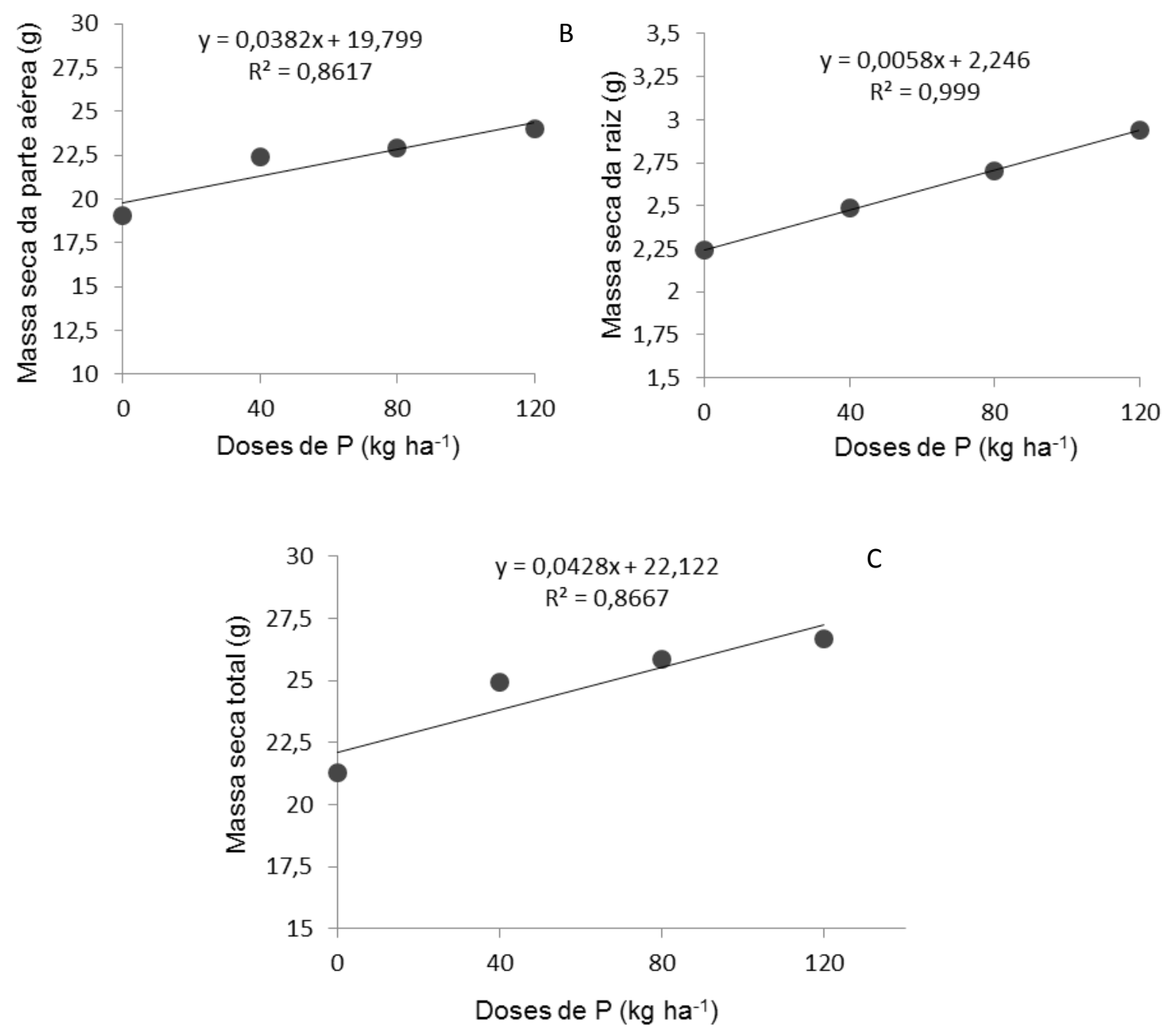

FIGURA 1. Massa seca da parte aérea (A), massa seca da raiz $(B)$ e massa seca total (C) de plantas de feijão-caupi adubadas com doses crescentes de P solúvel. Colorado do Oeste, RO (2017).

O teor de fósforo na parte área, conteúdo de fósforo na parte aérea, na raiz e na planta foram influenciadas significativamente $(p \leq 0,05)$ pelas doses crescentes de $\mathrm{P}$ no solo (Figura 2B, 3A, 3B e 3C), enquanto que o teor de fósforo na raiz respondeu significativamente apenas as fontes de P solúvel (Figura 2A). Quanto mais fósforo disponível no solo maior será o gradiente de concentração deste elemento, ocasionando, portanto, aumento no teor de $\mathrm{P}$ na parte aérea $\mathrm{e}$ incorporação desse nutriente na biomassa.

A adubação fosfatada incrementou as concentrações de $P$ na folha, sendo a máxima concentração de $P$ de $2,90 \mathrm{~g} \mathrm{~kg}^{-1}$, obtido na dose $120 \mathrm{~kg} \mathrm{ha}^{-1}$ (Figura 1B). Concentrações similares de $\mathrm{P}$ na folha para essa cultura, foi observada por Souza Rosal e Rocha (2013) que obtivram a concentração máxima de $P$ de $2,8 \mathrm{~g} \mathrm{~kg}^{-1} \mathrm{em}$ aplicação a lanço, utilizando doses que variaram de 0 a $160 \mathrm{~kg} \mathrm{ha}^{-1}$ de $\mathrm{P}_{2} \mathrm{O}_{5}$. As maiores concentrações observadas no presente estudo se justificam em função das maiores doses de $\mathrm{P}$ utilizadas, e do cultivo em solo com menores teores de argila.

Na Figura 2A, encontram-se os dados referentes ao teor de fósforo na raiz, onde houve diferença significativa entre as fontes utilizadas na semeadura (superfosfato simples e superfosfato triplo). Os valores dos teores de fósforo na raiz 
variaram de 2,06 g kg-1 (SFS) a 2,34 $\mathrm{g} \mathrm{kg}^{-1}$ (SFT). Esses valores estão de acordo com os encontrados por Malavolta et al. (1997), que consideram $2 \mathrm{~g} \mathrm{~kg}^{-1}$ a $3 \mathrm{~g} \mathrm{~kg}^{-1}$ adequados para a cultura.
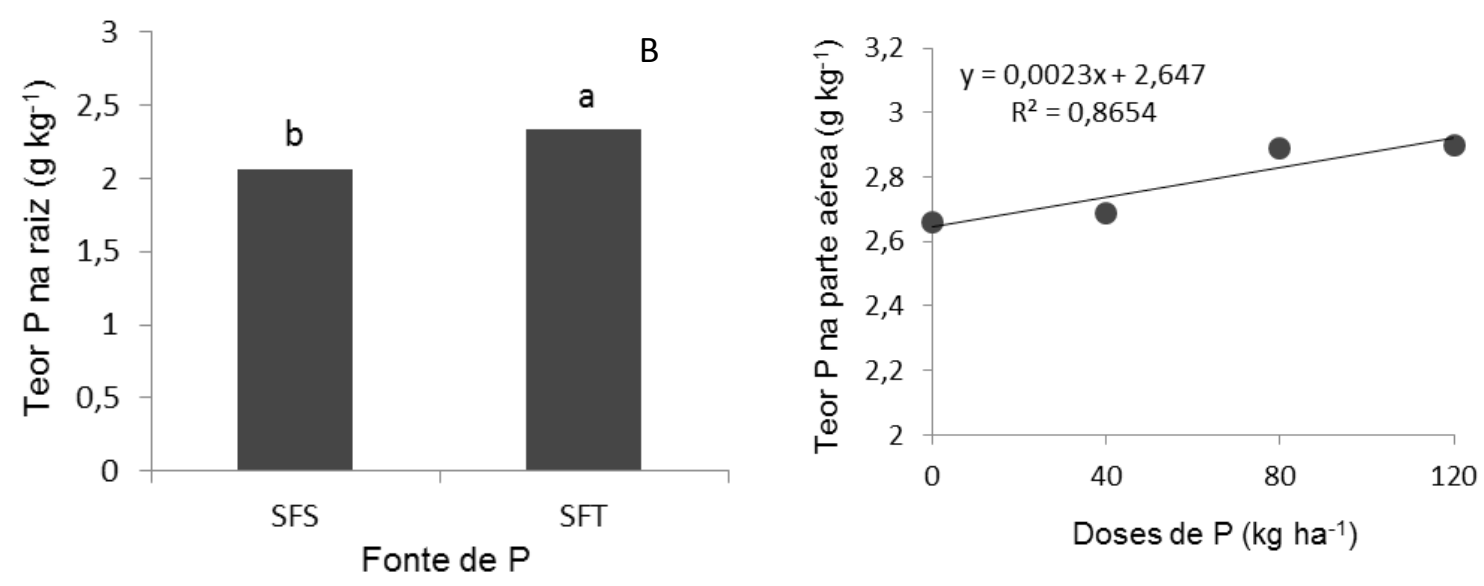

FIGURA 2. Teor de $P$ na raiz $(A)$ e teor de $P$ na parte área $(B)$ de plantas de feijãocaupi adubadas com diferentes doses e fontes $\mathrm{P}$ solúvel. Colorado do Oeste, RO (2017).
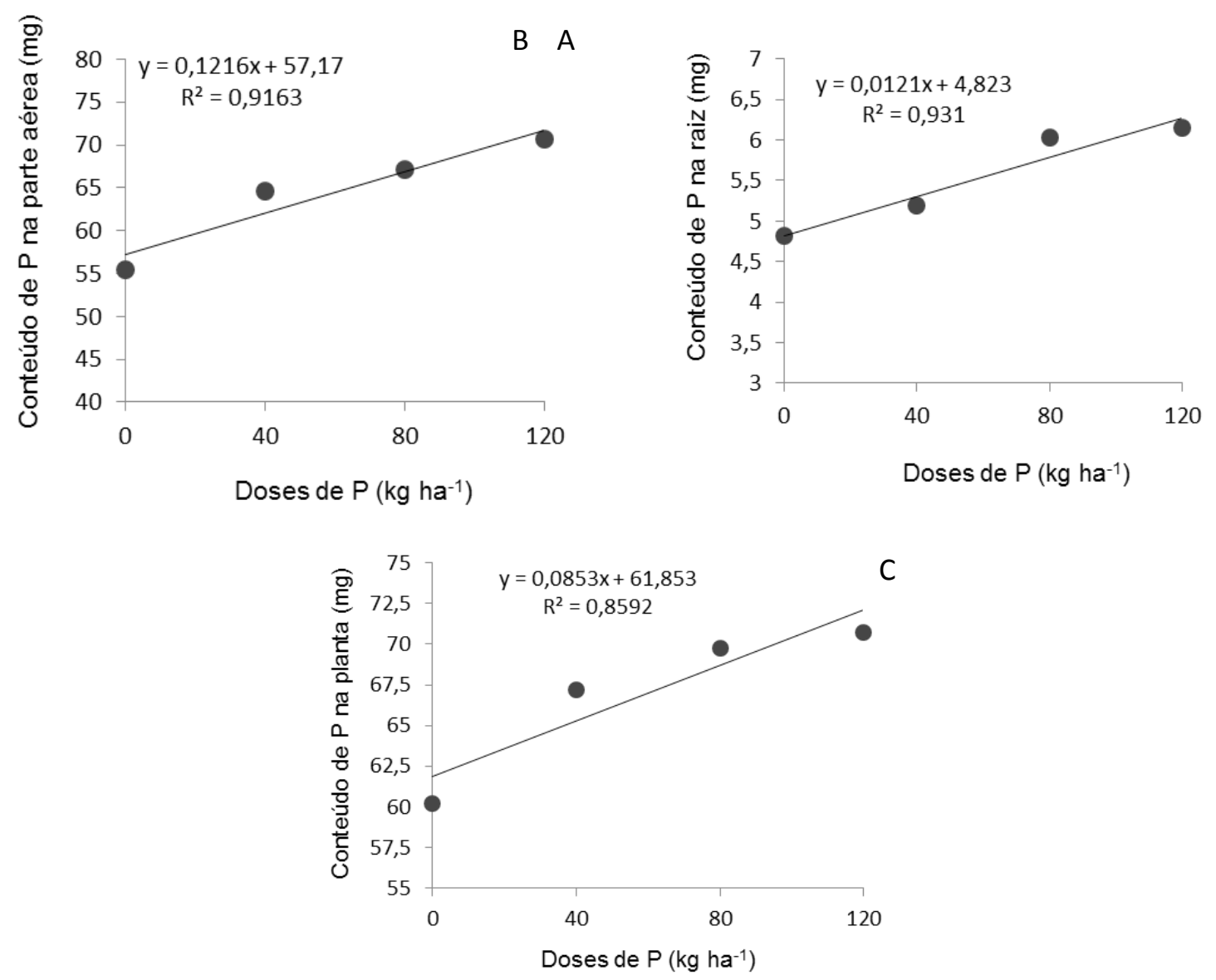

FIGURA 3. Conteúdo de $P$ na parte aérea $(A)$, conteúdo de $P$ na raiz $(B)$ e conteúdo de $P$ na planta $(C)$ de feijão-caupi adubadas com diferentes doses $P$ solúvel. Colorado do Oeste, RO (2017). 
A eficiência de utilização do $P$ respondeu linearmente ao incremento das doses de fósforo (Figura 4), correspondendo à capacidade de uma planta redistribuir e reutilizar os minerais de um órgão mais velho e senescente. A utilização do $P$ pelas variedades de feijão-caupi variou de $7,63-10,19 \mathrm{mg}$ de peso seco por $\mathrm{g}$ de $\mathrm{P}$ absorvido, concluindo que o estudo da eficiência de utilização do fósforo em sistemas produtivos é fundamental, pois à medida que a quantidade aplicada de $\mathrm{P}$ é incrementada, aumenta a EUP, e a medida que se ultrapassa a capacidade da planta em absorver o nutriente para produção, o P pode ser lixiviado ou acumular-se nos tecidos, reduzindo a eficiência de aproveitamento (ARAÚJO et al., 2015). Assim, a disponibilidade de $\mathrm{P}$ influenciou positivamente na capacidade de aproveitamento do nutriente pelas plantas de feijão-caupi.

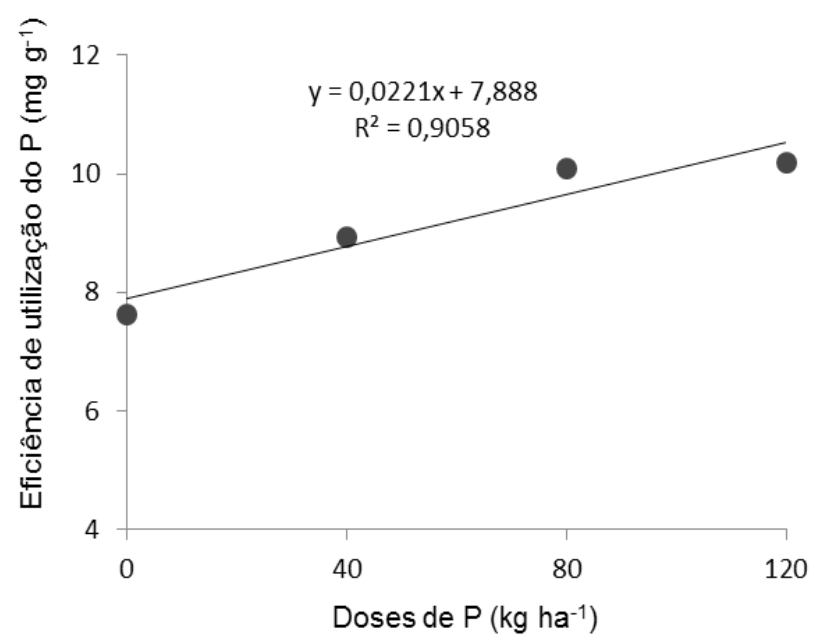

FIGURA 4. Eficiência de utilização do $P$ por plantas de feijão-caupi adubadas com diferentes doses P solúvel. Colorado do Oeste, RO (2017).

\section{CONCLUSÃO}

Existe variabilidade quanto à eficiência e reposta à aplicação de fósforo entre os genótipos de feijão-caupi. O genótipo Novaera mostrou-se mais eficiente quanto à absorção e transporte de fósforo.

O superfosfato triplo apresenta maior eficiência na absorção de $\mathrm{P}$ pelas raízes que o superfosfato simples.

O aumento nas doses de fósforo promove incremento nas concentrações e na eficiência de utilização do fósforo por plantas de feijão-caupi.

\section{AGRADECIMENTOS}

Os autores agradecem ao CNPq pela concessão de bolsa de iniciação científica ao segundo autor e ao Instituto Federal de Educação, Ciência e Tecnologia de Rondônia pela disponibilização de recursos.

\section{REFERÊNCIAS}

ALVARES, C.A.; STAPE, J.L.; SENTELHAS, P.C.; GONÇALVES, J.L.M.; SPAROVEK, G. Köppen's climate classification map for Brazil. Meteorologische Zeitschrift, v.22, p.711-728, 2013. Disponível em: < https://www.schweizerbart.de/content/papers/download/82078> 
ARAUJO, E.O., SANTOS, E.F., CAMACHO, M.A. Nutritional efficiency of cowpea varieties in the absorption of phosphorus. Agronomía Colombiana, n.30, v.3, p. 419-424, 2012. Disponível em: < http://agris.fao.org/agris-search/search.do? recordID $=$ CO2013007243>

ARAUJO, E.O; MARTINS, M.R.; VITORINO, A.C.T.; MERCANTE, F.M.; URQUIAGA, S.S. Effect of nitrogen fertilization associated with diazotrophic bacteria inoculation on nitrogen use efficiency and its biological fixation by corn determined using ${ }^{15} \mathrm{~N}$. African Journal Microbiology Research, v.9, n.9, p. 643-650, 2015. Disponível em:<http://academicjournals.org/journal/AJPS/article-full-text-pdf/718D35F59497> DOI: 10.5897/AJPS2016.1394

BARBER, S.A. Mecanismos de absorção de fósforo sob condições de estresse ambiental, p. 233-237. In: Simpósio Internacional sobre Estresse Ambiental. 1, Belo Horizonte. Anais... Sete Lagoas, Empresa Brasileira de Pesquisa Agropecuária. 1995.

EMBRAPA - Empresa Brasileira de Pesquisa Agropecuária ; Socioeconomia. Disponível em: <http://www.cnpaf.embrapa.br/socioeconomia/index.htm>Acesso em: 10 set. 2017.

EMBRAPA - Empresa Brasileira de Pesquisa Agropecuária ; Manual de análises químicas de solos, plantas e fertilizantes. - 2. Ed, Brasília., Embrapa Informação Tecnológica, 2009. 627 p.

FAO - Food and Agriculture Organization -FAO FAOSTAT. Crops. Cow peas, dry. Disponível em: <http://faostat3.fao.org/home/index.html\#DOWNLOAD>. Acesso em: 08 ago. 2017.

KARIKARI, B.; ARKORFUL, E.; ADDY, S. Growth, Nodulation and Yield Response of Cowpea to Phosphorus Fertilizer Application in Ghana. Journal of Agronomy, n.14, v.4,p.234-240,2015. Disponível em: <http://scialert.net/qredirect.php? doi=ja.2015.234.240\&linkid=pdf> DOI: 10.3923/ja.2015.234.240

NKAA, F.A.; NWOKEOCHA, O.W.; IHUOMA, O. Effect of phosphorus fertilizer on growth and yield of cowpea (Vigna unguiculata). IOSR Journal of Pharmacy and Biological Sciences, n. 9, v.5, p. 74-82, 2014. Disponivel em:< http://www.iosrjournals.org/iosr-jpbs/papers/Vol9-issue5/Version-4/N09547482.pdf> DOI: $10.9790 / 3008-09547482$.

ROCHA, W. S. Inoculação e doses de fósforo em feijão-caupi no sul do Estado do Tocantins. Gurupi: UFT, 2016. 56 p. Dissertação (Mestrado) - Curso de PósGraduação em Agronomia, Área de Concentração em Produção Vegetal, Universidade Federal do Tocantins, Gurupi, 2016.

SIDDIQI, M. Y.; GLASS, A. D. M. Utilization index: a modified approach to the estimation and comparison of nutrient utilization efficiency in plants. Journal of Plant Nutrition, v. 4, n.3, p. 289-302, 1981.Disponível em: < https://doi.org/10.1080/01904168109362919> 
SILVA, A.J.; UCHÔA, S.C.P.; ALVES, J.M.A.; LIMA, A.C.S.;SANTOS, C.S.V.; OLIVEIRA, J.M.F.; MELO, V.F. Resposta do feijão-caupi à doses e formas de aplicação de fósforo em Latossolo Amarelo do Estado de Roraima. Acta Amazonica, v.40, n. 1, p. 31-36, 2010a. Disponível em:< http://dx.doi.org/10.1590/S0044-59672010000100004>

SILVA, E.F.; ARAÚJO, A.S.F.; SANTOS, V.B.; NUNES, A.P.L.; CARNEIRO, R.F.V. Fixação biológica do N2 em feijão-caupi sob diferentes doses e fontes de fósforo solúvel. Bioscience Journal, v. 26, n. 3, p. 394-402, 2010b. Disponível em: < file:///C:/Users/Erica\%20Araujo/Downloads/7117-29760-1-PB\%20(1).pdf >

SOUZA ROSAL, C.J. ROCHA, W. S. Doses de fósforo e zinco na cultura do feijão-caupi. Jaboticabal: UNESP, 2013. 76 p. Tese (Doutorado) - Curso de PósGraduação em Agronomia, Área de Concentração em Produção Vegetal, Universidade Estadual Paulista, Faculdade de Agronomia e Veterinária, Jaboticabal, 2013.

SWIADER, J. M. CHYAN, Y.; FREIJI, F. G. Genotypic differences in nitrate uptake and utilization efficiency in pumpkin hybrids. Journal of Plant Nutrition, v.17, n.10, p.1687-1699, 1994. Disponível em: < https://doi.org/10.1080/01904169409364840>

WANG, X.; SHEN, J.; LIAO, H. Acquisition or utilization, which is more critical for enhancing phosphorus efficiency in modern crops? Plant Science, n.179, 302-306, 2010. Disponível em: $\quad$ http://www.rbcscau.cn/sites/files/Wang_et_al_Plant_Science_2010.pdf>.doi:10.1016/j.plantsci.2010 .06 .007 